\title{
Monetary costs of dietary energy reported by young Japanese women: association with food and nutrient intake and body mass index
}

\author{
Kentaro Murakami ${ }^{1}$, Satoshi Sasaki ${ }^{1, *}$, Hitomi Okubo ${ }^{2}$, Yoshiko Takahashi $^{1}$, \\ Yoko Hosoi ${ }^{1}$ and Mami Itabashi ${ }^{1}$ \\ 'Nutritional Epidemiology Program, National Institute of Health and Nutrition, Toyama 1-23-1, Shinjuku-ku, \\ Tokyo 162-8636, Japan: ${ }^{2}$ Department of Nutrition Sciences, Kagawa Nutrition University, Saitama, Japan
}

Submitted 17 May 2006: Accepted 16 November 2006: First published online 18 June 2007

\begin{abstract}
Objective: Little is known about the relationship of monetary diet costs to dietary intake and obesity, particularly in non-Western populations. This study examined monetary cost of dietary energy in relation to diet quality and body mass index (BMI) among young Japanese women.

Design: Dietary intake was assessed by a validated, self-administered, diet history questionnaire. Diet costs were estimated using retail food prices. Monetary cost of dietary energy (Japanese yen $1000 \mathrm{kcal}^{-1}$ ) was then calculated. BMI was computed from self-reported body weight and height.

Subjects: A total of 3931 female Japanese dietetic students aged 18-20 years.

Results: Monetary cost of dietary energy was positively associated with intakes of fruits, vegetables, fish and shellfish, and pulses; however, higher monetary cost of dietary energy was also associated with higher consumption of fat and oil, meat and energy-containing beverages, and lower consumption of cereals (rice, bread and noodles) (all $P$ for trend $<0.01$ ). At the nutrient level, monetary cost of dietary energy was positively associated with intakes of dietary fibre and key vitamins and minerals, but also associated positively with intakes of fat, saturated fatty acids, cholesterol and sodium, and negatively with carbohydrate intake (all $P$ for trend <0.0001). After adjustment for possible confounders, monetary cost of dietary energy was quite weakly but significantly negatively associated with BMI ( $P$ for trend $=0.0197$ ).

Conclusions: Increasing monetary cost of dietary energy was associated with both favourable and unfavourable dietary intake patterns and a quite small decrease in BMI in young Japanese women.
\end{abstract}

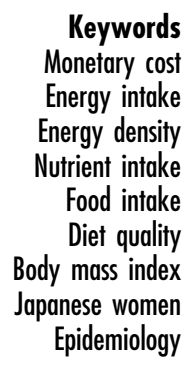

While food choice is influenced by a large number of factors ${ }^{1}$, the price of food is clearly an important determinant $^{2,3}$. An inverse relationship exists between the energy density of foods (energy derived from foods per edible weight of foods) and energy cost (monetary cost of foods per energy derived from foods) ${ }^{4}$. Generally, energy-dense and nutrient-dilute foods such as cereals, fats and oils, and sugar and sweets provide dietary energy at the lowest cost. Conversely, the cost per calorie of energy-dilute and nutrient-dense foods including fish and shellfish, vegetables and fruit is much higher.

If healthier foods cost more then so too will healthier diets, suggesting that consumers with limited financial resources might select energy-dense and nutrient-dilute diets as a means of saving money. Observational studies (albeit a limited number) on the cost of freely chosen diets have consistently shown that healthful diets are more expensive than less healthful diets ${ }^{5-10}$. To our knowledge, however, all studies of self-selected diets and monetary costs have been conducted in European countries, with none reported in Asian countries, including Japan.

In contrast to Western populations, Japanese obtain the largest part of their energy intake from rice $(29 \%)^{11}$. Further, fat intake is relatively low $(\leq 30 \% \text { energy })^{12}$. The relationship of dietary costs to dietary intake and diet quality may therefore differ between Western and Japanese populations. Here, we examined the monetary cost of dietary energy in relation to food and nutrient intake and energy density in a group of young Japanese women. Given recent findings from Spain of the higher monetary costs of healthy dietary patterns associated with a lower body mass index $(\mathrm{BMI})^{10}$, we also examined the association between monetary cost of dietary energy and BMI. 


\section{Subjects and methods}

\section{Subjects and survey procedure}

The present study was based on a self-administered questionnaire survey among dietetic students $(n=4679)$ from 54 universities, colleges and technical schools in 33 of 47 prefectures in Japan. Staff at each institution distributed two questionnaires on dietary habits and other lifestyle items during the preceding month at orientation sessions or early lectures for freshman students who entered dietetic courses in April 2005, in most institutions within 2 weeks after the course began. Students filled out the questionnaires during the session, lecture or at home, and then submitted the completed forms to staff at each institution. The staff then checked the responses according to the survey protocol. When missing answers or logical errors were identified, the students were asked to complete the questionnaire again. The staff then mailed the completed questionnaires to the survey centre, where the answers were checked once more. Problematic questionnaires were returned to the staff at the respective institution, and the students were asked to complete the questionnaires again. All questionnaires were thus checked at least once each by staff at the respective institution and at the survey centre. Most surveys were completed by May 2005. The protocol of the study was approved by the Ethics Committee of the National Institute of Health and Nutrition.

In total, 4394 students (4168 women and 226 men) answered two questionnaires (response rate $=93.9 \%$ ). For the present analysis, we selected female subjects aged 18-20 years $(n=4060)$. We then excluded those who were in an institution where the survey had been conducted at the end of May $(n=98)$, those with extremely low or high energy intake $\left(<500 \mathrm{kcalday}^{-1}\right.$ or $\left.>4000 \mathrm{kcalday}^{-1}\right) \quad(n=23)$ and those with missing information on the variables used $(n=12)$. As some subjects were in more than one exclusion category, the final analysis sample comprised 3931 women.

\section{Dietary intakes}

Dietary habits during the preceding month were assessed using a previously validated, self-administered, diet history questionnaire (DHQ $)^{13-15}$. This is a 16-page structured questionnaire that consists of the following seven sections: general dietary behaviour; major cooking methods; consumption frequency and amount of six alcoholic beverages; consumption frequency and semiquantitative portion size of 122 selected food and non-alcoholic beverage items; dietary supplements; consumption frequency and semi-quantitative portion size of 19 cereals usually consumed as staple foods (rice, bread and noodles) and miso (fermented soybean paste) soup; and open-ended items for foods consumed regularly (once a week or more) but not appearing in the DHQ. Items and portion sizes were derived primarily from data in the National Nutrition Survey of Japan and several recipe books for Japanese dishes ${ }^{13}$.

Estimates of dietary intake for 148 food and beverage items, energy and nutrients were calculated using an ad hoc computer algorithm for the DHQ based on the Standard Tables of Food Composition in Japan ${ }^{16}$. Information on dietary supplements and data from the open-ended questionnaire items were not used in the calculation. Energy-adjusted values of dietary intake were calculated using the percentage of energy for macronutrients and the amount per 1000 kcal for dietary fibre, vitamins, minerals and foods. Alcohol intake was not used because of an extremely low mean intake $\left(0.8 \mathrm{~g} \mathrm{day}^{-1}\right)$. Dietary energy density $\left(\mathrm{kcal} \mathrm{g}^{-1}\right.$ ) was calculated by dividing total energy intake by the estimated edible weight of all foods and caloric beverages consumed (excluding alcohol). Detailed descriptions of the methods used to calculate dietary intake and the validity of the DHQ have been published elsewhere ${ }^{13-15}$. Pearson correlation coefficients between the DHQ and 3-day estimated dietary records were 0.48 for energy, $0.48-0.55$ for energy-yielding nutrients (excluding alcohol) and 0.19-0.68 for vitamins and minerals among 47 women $^{13}$. In addition, the Pearson correlation coefficients between the DHQ and 16-day weighed dietary records among 92 women were 0.69 for total dietary fibre, 0.40 for energy density and 0.33 for edible weight consumed, and the Spearman correlation coefficients for food groups ranged from 0.28 to 0.59 (Sasaki S, unpublished observations, 2004).

\section{Dietary costs}

Monetary costs of habitual diets obtained from the DHQ (Japanese yen day ${ }^{-1}$ ) were calculated by multiplying the amount of food consumed from the DHQ $\left(\mathrm{g} \mathrm{day}^{-1}\right.$ ) by the estimated price of each food (Japanese yen $\mathrm{g}^{-1}$ ) and summing the products ( 1 Japanese yen $=0.007$ Euros $=$ 0.008 US dollars in April 2006). The procedure for estimating costs was based on the assumption that all foods were purchased and then prepared and consumed at home. Alcoholic beverages (six items), non-alcoholic and non-caloric beverages (four items), drinking water, noodle soup, and water for miso soup were excluded from calculation. The price of each food was obtained mainly from the National Retail Price Survey $2004^{17}$ (122 of 135 items; 90\%). This survey is conducted annually in 167 villages, towns and cities, and average prices were calculated as mean values of all survey areas, weighted for population size. For food items whose prices are not published in the National Retail Price Survey (13 of 135 items; 10\%), prices were taken from the websites of nationally distributed supermarket (Seiyu, Japan) and fast-food restaurant (McDonalds, Japan and Mister Donut, Japan) chains. Sale prices were not used to determine costs. Costs of combined foods such as pizza were calculated using prices of frozen equivalents. Calculation included correction for preparation and waste 
Table 1 Monetary cost of dietary energy of each food ${ }^{*}$

\begin{tabular}{|c|c|}
\hline Food group & Food item (Japanese yen $\left.1000 \mathrm{kcal}^{-1}\right) \dagger$ \\
\hline Rice & $\begin{array}{l}\text { White rice (148), white rice mixed with barley (170), white rice with rice germ (149), 50\% polished rice (149), } 70 \% \\
\text { polished rice (148), brown rice (151) }\end{array}$ \\
\hline Bread & $\begin{array}{l}\text { White bread (154), butter roll (163), croissant (94), pizza (594), Japanese-style pancake (528), pancake (146), } \\
\text { cornflakes (260) }\end{array}$ \\
\hline Noodles & $\begin{array}{l}\text { Japanese noodles (buckwheat and Japanese wheat noodles) (197), instant noodles (418), Chinese noodles } \\
\text { (361), spaghetti (126) }\end{array}$ \\
\hline Potatoes & $\begin{array}{l}\text { Potato chips (268), French fries (466), other potatoes (390), sweet potatoes, yams and taros (624), konnyaku } \\
\text { (devil's tongue jelly) (8639) }\end{array}$ \\
\hline Confectioneries & $\begin{array}{l}\text { Rice crackers (301), snacks made from wheat flour (282), Japanese sweets with azuki beans (598), Japanese } \\
\text { sweets without azuki beans (564), cakes (758), cookies and biscuits (265), chocolates (242), candies, caramels } \\
\text { and chewing gum (1297), jellies (841), doughnuts (411), cake bread (280), jam and marmalade (538), sugar for } \\
\text { coffee and tea (48), sugar used during cooking (48) }\end{array}$ \\
\hline Fat and oil & Margarine (72), mayonnaise (83), salad dressing (283), oils used during cooking (93), butter (211) \\
\hline Pulses & $\begin{array}{l}\text { Tofu (429), tofu products (582), natto (443), boiled beans }(216), \text { miso as seasoning (179), miso in miso soup } \\
(179) \text {, peanuts }(247) \text {, other nuts }(231)\end{array}$ \\
\hline Fish and shellfish & $\begin{array}{l}\text { Dried fish (1005), small fish with bones (1534), canned tuna (667), eel (2113), white meat fish (2774), blue-back } \\
\text { fish (812), red meat fish (1979), ground fish meat products (1048), shrimp (5498), squid and octopus (2488), } \\
\text { oysters (4461), other shellfish (3392), fish eggs (2727), boiled fish, shellfish and seaweed in soy sauce (993), } \\
\text { salted fish intestine (1608) }\end{array}$ \\
\hline Meat & Ground beef and pork (1093), chicken (782), pork (712), beef (1563), liver (987), ham and sausages (935), bacon (545) \\
\hline Eggs & Eggs (247) \\
\hline Dairy products & $\begin{array}{l}\text { Full-fat milk (302), low-fat milk (439), skimmed milk (439), sweetened yoghurt (585), non-sweetened yoghurt } \\
\text { (632), moderately sweetened yoghurt (608), cheese (436), cottage cheese (1407), ice cream (687), coffee } \\
\text { cream (908) }\end{array}$ \\
\hline Vegetables & 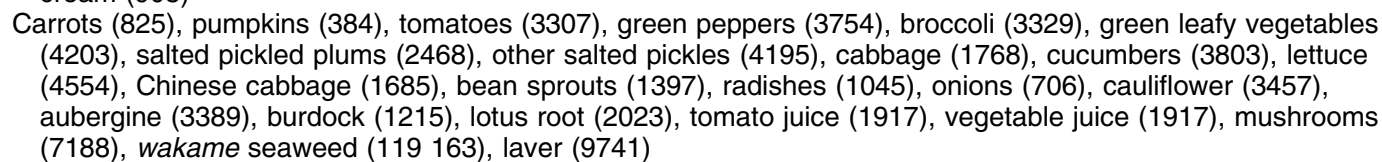 \\
\hline Fruits & $\begin{array}{l}\text { Oranges (1287), bananas (387), apples (1030), strawberries (4396), grapes (2385), peaches (2513), pears } \\
(1330), \text { persimmons }(1038) \text {, kiwi fruits }(1606) \text {, melons }(2127) \text {, watermelons }(1218) \text {, raisins (365), canned fruits } \\
\text { (480), 100\% fruit juice }(512) \text {, other fruit juice }(421)\end{array}$ \\
\hline $\begin{array}{l}\text { Non-alcoholic, } \\
\text { energy-containing } \\
\text { beverages }\end{array}$ & Cocoa (993), lactic and bacteria beverages (278), soft drinks (528), nutritional supplement drinks (1679) \\
\hline Other foods & $\begin{array}{l}\text { Ketchup (432), non-oil salad dressing (1305), soy sauce (400), curry and roux in stew (182), corn soup (514), } \\
\text { Chinese soup (514), nutritional supplement bars }(525) \text {, artificial sweeteners }(2568) \text {, table salt }(11(/ 100 \mathrm{~g})) \text {, salt } \\
\text { used during cooking }(11(/ 100 \mathrm{~g}))\end{array}$ \\
\hline
\end{tabular}

${ }^{\star}$ Foods not listed above (six alcoholic beverages, four non-alcoholic and non-caloric beverages, drinking water, noodle soup, water for miso soup) were not used for the calculation of diet costs.

+1 Japanese yen $=0.007$ Euros $=0.008$ US dollars in April 2006 .

(e.g. trimming and peeling of vegetables and fruits, removal of bones and skin from fish). Monetary cost of dietary energy (Japanese yen $1000 \mathrm{kcal}^{-1}$ ) was calculated by dividing the estimated daily cost of the diet (Japanese yen day $^{-1}$ ) by the daily energy intake $\left(\mathrm{kcalday}^{-1}\right)$ and multiplying by 1000 . The monetary cost of dietary energy of each food is listed in Table 1.

\section{BMI}

Body weight and height were self-reported as part of the DHQ. BMI was calculated as weight (kg) divided by the square of height $(\mathrm{m})$.

\section{Other variables}

Residential areas, reported in the 12-page lifestyle questionnaire, were grouped into six regions (Hokkaido and Tohoku; Kanto; Hokuriku and Tokai; Kinki; Chugoku and Shikoku; Kyushu) based on blocks used in the National Nutrition Survey in Japan ${ }^{12}$ and hereafter referred to as 'residential block'. The residential areas were also grouped into three categories according to population size (city with population $\geq 1$ million; city with population $<1$ million; town and village) and hereafter referred to as 'size of residential area'. The lifestyle questionnaire also assessed living status (living alone; living with family; living with others), current smoking (yes; no) and whether currently trying to lose weight (yes; no).

Subjects additionally reported in the questionnaire the time they usually got up and went to bed, which was used to calculate sleeping hours, and the frequency and duration of high- and moderate-intensity activities, walking and sedentary activities. Each activity was assigned a metabolic equivalent task (MET) value from a previously published table, namely 0.9 for sleeping, 7.0 for high-intensity activity, 5.0 for moderate-intensity activity, 3.3 for walking and 1.5 for sedentary activity ${ }^{18,19}$. The number of hours spent per day on each activity was multiplied by its MET value, and all MET-hour products were summed to give a total MET-hour score for the day, 
which essentially corresponded to the number of kilocalories per kilogram of body weight expended by the individual during the day. The standard value of basal metabolic rate for Japanese people was also expressed as the number of kilocalories per kilogram of body weight expended by an individual during the day. Physical activity level was then calculated by dividing the total MET-hour score by the standard value of basal metabolic rate for Japanese women aged 18-29 years ${ }^{20}$. Current alcohol drinking (yes; no), current dietary supplement use (yes; no) and rate of eating (very slow; relatively slow; medium; relatively fast; very fast) were assessed using the DHQ.

\section{Underreporting of energy intake}

Underreporting of energy intake is an ongoing controversy in studies using self-report instruments to collect dietary information ${ }^{21,22}$. To estimate the prevalence of energy underreporting in this population, the ratio of reported energy intake to basal metabolic rate (estimated according to a published equation for Japanese women aged 18-29 years using reported body weight ${ }^{20}$ ) was computed. Using the Goldberg cut-off method ${ }^{21}$ recently re-evaluated by $\mathrm{Black}^{23}$, a ratio of 1.09 was calculated as the lower cut-off point for reasonable habitual energy intake. Persons with ratios of energy intake to basal metabolic rate $<1.09$ were considered by this technique to be energy underreporters $(n=666 ; 17 \%)$. Results in all subjects and those obtained after exclusion of energy underreporters did not differ materially. Therefore, we only present the analyses of all subjects.

\section{Statistical analysis}

All statistical analyses were performed using SAS statistical software, version 8.2 (SAS Institute Inc.). We calculated both crude and multivariate-adjusted means of dietary intake and BMI by quintile categories of monetary cost of dietary energy. Confounding variables included in the multivariate models were residential block (Hokkaido and Tohoku; Kanto; Hokuriku and Tokai; Kinki; Chugoku and Shikoku; Kyushu), size of residential area (city with population $\geq 1$ million; city with population $<1$ million; town and village), living status (living with family; living alone; living with others), current smoking (yes; no), current alcohol drinking (yes; no), current dietary supplement use (yes; no), currently trying to lose weight (yes; no), rate of eating (very slow; relatively slow; medium; relatively fast; very fast), and physical activity level (continuous) and energy intake ( $\mathrm{kcal} \mathrm{day}^{-1}$, continuous) for variables except for energy intake. For analyses on BMI, intakes of protein ( $\%$ of energy, continuous), fat ( $\%$ of energy, continuous) and dietary fibre (g $1000 \mathrm{kcal}^{-1}$, continuous) were further included as confounding factors. Linear trends with increasing levels of monetary cost of dietary energy were tested by assigning to each participant the median value for the category and modelling this value as a continuous variable. All reported $P$-values are two-tailed and were considered statistically significant at the $<0.05$ level.

\section{Results}

Subject characteristics are shown in Table 2. Women in the higher quintiles of monetary cost of dietary energy tended to live in areas with larger populations, live with family, use alcohol and dietary supplements, be slow eaters and trying to lose weight. Women in the higher quintiles of monetary cost of dietary energy had higher mean values of body weight, BMI and physical activity level. Major contributors to total dietary cost were fish and shellfish (16\%), meat (16\%), vegetables (16\%), confectioneries (12\%) and rice (9\%) (Table 3). Women in the higher quintiles of monetary cost of dietary energy had lower mean values of diet cost for cereals (except noodles). Mean costs of all other foods were higher in women in the higher quintiles of monetary cost of dietary energy.

Table 4 shows the association between monetary cost of dietary energy and dietary intake. Increasing monetary cost of dietary energy was associated with both favourable and unfavourable dietary intake patterns. At the food level, monetary cost of dietary energy was positively associated with consumption of vegetables, fruits, fish and shellfish, pulses, potatoes and dairy products, but also associated positively with intakes of fat and oil, meat and energy-containing beverages, and negatively with intakes of cereals (rice, bread and noodles) (all $P$ for trend <0.01). At the nutrient level, monetary cost of dietary energy was directly associated with intakes of protein, dietary fibre and key vitamins (such as vitamins A, D, E, C, thiamin and riboflavin) and minerals (such as potassium, iron, calcium and magnesium), while monetary cost of dietary energy was associated positively with intakes of fat, saturated fatty acids, cholesterol and sodium, and negatively with carbohydrate intake (all $P$ for trend $<0.0001$ ). Monetary cost of dietary energy was positively associated with both energy intake and edible weight consumed (both $P$ for trend $<0.0001$ ), but the magnitude of differences between quintiles was larger in edible weight consumed than in energy intake. As a result, monetary cost of dietary energy was negatively associated with energy density ( $P$ for trend $<0.0001$ ). Adjustment for possible confounding factors did not materially change the associations between monetary cost of dietary energy and dietary intakes (data not shown) except for noodles ( $P$ for trend $=0.88$ ), confectioneries ( $P$ for trend $=0.0076$; negative relationship $)$ and dairy products $(P$ for trend $=0.07$ )

Table 5 shows the association between monetary cost of dietary energy and BMI. Monetary cost of dietary energy was quite weakly but significantly negatively associated with BMI in both crude (model 1: $P$ for trend $=0.0224$ ) and multivariate (model 2: $P$ for trend $=0.0197$ ) analyses. 
Table 2 Subject characteristics according to quintile category of monetary cost of dietary energy*

\begin{tabular}{|c|c|c|c|c|c|c|c|}
\hline & \multirow[b]{2}{*}{ Total $(n=3931)$} & \multicolumn{5}{|c|}{ Quintile category of monetary cost of dietary energy (Japanese yen $\left.1000 \mathrm{kcal}^{-1}\right) \dagger$} & \multirow[b]{2}{*}{$P \ddagger$} \\
\hline & & $\begin{array}{c}\text { 1st }(n=786) \\
(219-400)\end{array}$ & $\begin{array}{l}\text { 2nd }(n=786) \\
\quad(401-445)\end{array}$ & $\begin{array}{l}\text { 3rd }(n=786) \\
\quad(446-486)\end{array}$ & $\begin{array}{l}\text { 4th }(n=787) \\
(487-537)\end{array}$ & $\begin{array}{l}\text { 5th }(n=786) \\
(538-1389)\end{array}$ & \\
\hline $\begin{array}{l}\text { Monetary cost of dietary energy } \\
\left(\text { Japanese yen } 1000 \mathrm{kcal}^{-1}\right)\end{array}$ & $472 \pm 89$ & $360 \pm 32$ & $424 \pm 13$ & $466 \pm 11$ & $511 \pm 15$ & $601 \pm 74$ & $<0.0001$ \\
\hline $\begin{array}{l}\text { Median monetary cost of dietary energy } \\
\left(\text { Japanese yen } 1000 \mathrm{kcal}^{-1}\right)\end{array}$ & 466 & 366 & 424 & 466 & 511 & 580 & \\
\hline Age (years) & $18.1 \pm 0.3$ & $18.1 \pm 0.4$ & $18.1 \pm 0.3$ & $18.1 \pm 0.3$ & $18.1 \pm 0.3$ & $18.1 \pm 0.3$ & 0.30 \\
\hline Body height $(\mathrm{cm})$ & $157.9 \pm 5.3$ & $158.0 \pm 5.3$ & $157.9 \pm 5.4$ & $157.7 \pm 5.4$ & $157.9 \pm 5.3$ & $158.0 \pm 5.3$ & 0.86 \\
\hline Body weight (kg) & $52.3 \pm 7.7$ & $52.5 \pm 7.7$ & $52.7 \pm 8.0$ & $52.0 \pm 7.3$ & $52.4 \pm 7.8$ & $51.9 \pm 7.6$ & 0.05 \\
\hline Body mass index $\left(\mathrm{kg} \mathrm{m}^{-2}\right)$ & $21.0 \pm 2.8$ & $21.1 \pm 2.9$ & $21.1 \pm 2.8$ & $20.9 \pm 2.7$ & $21.0 \pm 3.0$ & $20.8 \pm 2.7$ & 0.02 \\
\hline Physical activity level & $1.45 \pm 0.16$ & $1.43 \pm 0.14$ & $1.44 \pm 0.16$ & $1.45 \pm 0.17$ & $1.45 \pm 0.14$ & $1.46 \pm 0.16$ & $<0.0001$ \\
\hline Residential block & & & & & & & 0.92 \\
\hline Hokkaido and Tohoku & $386(10)$ & $84(11)$ & $94(12)$ & $65(8)$ & $69(9)$ & $74(9)$ & \\
\hline Kanto & $1351(34)$ & $246(31)$ & 259 (33) & $281(36)$ & $279(36)$ & $286(37)$ & \\
\hline Hokuriku and Tokai & $544(14)$ & $123(16)$ & $117(15)$ & 99 (13) & $102(13)$ & $103(13)$ & \\
\hline Kinki & 780 (20) & $136(17)$ & $154(20)$ & $172(22)$ & $171(22)$ & 147 (19) & \\
\hline Chugoku and Shikoku & $424(11)$ & $111(14)$ & $91(12)$ & $86(11)$ & $61(8)$ & $75(10)$ & \\
\hline Kyushu & $446(11)$ & $86(11)$ & $71(9)$ & $84(11)$ & $104(13)$ & 101 (13) & \\
\hline Size of residential area & & & & & & & 0.01 \\
\hline City with population $\geq 1$ million & $782(20)$ & $132(17)$ & $146(19)$ & $160(20)$ & $163(21)$ & $181(23)$ & \\
\hline City with population $<1$ million & $2550(65)$ & $534(68)$ & $513(65)$ & $520(66)$ & $483(61)$ & $500(64)$ & \\
\hline Town and village & $599(15)$ & $120(15)$ & $127(16)$ & $107(14)$ & 140 (18) & 105 (13) & \\
\hline Living status & & & & & & & $<0.0001$ \\
\hline Living with family & 3484 (89) & $607(77)$ & $690(88)$ & $726(92)$ & $718(91)$ & $743(95)$ & \\
\hline Living alone & $365(9)$ & $155(20)$ & $75(10)$ & $47(6)$ & $56(7)$ & $32(4)$ & \\
\hline Living with others & $82(2)$ & $24(3)$ & $21(3)$ & $13(2)$ & $13(2)$ & $11(1)$ & \\
\hline Current smoking & & & & & & & 0.26 \\
\hline No & $3873(99)$ & $773(98)$ & $771(98)$ & 776 (99) & 776 (99) & 777 (99) & \\
\hline Yes & $58(1)$ & $13(2)$ & $15(2)$ & $10(1)$ & $11(1)$ & $9(1)$ & \\
\hline Current alcohol drinking & & & & & & & 0.007 \\
\hline No & $3178(81)$ & $654(83)$ & $644(82)$ & $636(81)$ & $628(80)$ & $616(78)$ & \\
\hline Yes & $753(19)$ & $132(17)$ & $142(18)$ & $150(19)$ & $159(20)$ & $170(22)$ & \\
\hline Current dietary supplement use & & & & & & & $<0.0001$ \\
\hline No & 3206 (82) & $677(86)$ & $668(85)$ & $629(80)$ & $625(79)$ & $608(77)$ & \\
\hline Yes & $725(18)$ & $109(14)$ & $118(15)$ & $157(20)$ & $162(21)$ & $178(23)$ & \\
\hline Currently trying to lose weight & & & & & & & $<0.0001$ \\
\hline No & $2511(64)$ & $558(71)$ & $524(67)$ & $499(63)$ & $476(60)$ & $453(58)$ & \\
\hline Yes & $1420(36)$ & 228 (29) & 262 (33) & $287(37)$ & $311(40)$ & $333(42)$ & \\
\hline Rate of eating & & & & & & & $<0.0001$ \\
\hline Very slow & $241(6)$ & $36(5)$ & $33(4)$ & $43(5)$ & $67(9)$ & $62(8)$ & \\
\hline Relatively slow & $1077(27)$ & $197(25)$ & $194(25)$ & $226(29)$ & $222(28)$ & $239(30)$ & \\
\hline Medium & $1149(29)$ & $245(31)$ & $251(32)$ & $220(28)$ & $210(27)$ & $223(28)$ & \\
\hline Relatively fast & 1303 (33) & 263 (33) & $279(36)$ & 264 (34) & 262 (33) & $234(30)$ & \\
\hline Very fast & $161(4)$ & $45(6)$ & $29(4)$ & $33(4)$ & $26(3)$ & $28(4)$ & \\
\hline
\end{tabular}


This negative relationship remained statistically significant after further adjustment for macronutrient and dietary fibre intakes (model 3: $P$ for trend $=0.0301$ ).

\section{Discussion}

To date, no information has appeared on the association between dietary costs and diet quality in Japanese populations, among whom rice is a major staple food and whose proportion of energy intake derived from fat is relatively low compared with Western people. In this study of young Japanese women, increasing monetary cost of dietary energy was associated with both favourable and unfavourable dietary intake patterns. Additionally, monetary cost of dietary energy was quite weakly inversely associated with BMI after controlling for possible confounders.

We found that higher monetary cost of dietary energy was associated with higher consumption of not only 'healthy' foods such as vegetables, fruits, fish and shellfish, and pulses, but also 'unhealthy' foods such as fat and oil, meat and energy-containing beverages. Increasing monetary cost of dietary energy was also associated with decreased intake of cereals, particularly rice. These findings are not consistent with previous Western studies. Diets high in fruits and vegetables and low in fats and sweets were associated with higher diet costs in French adults ${ }^{7}$. A study of UK women found that high adherence to a healthy dietary pattern was associated with higher monetary costs 6 . For Japanese people, cereals (particularly rice) are staple foods and are consumed at almost every meal, accompanied by a main and several side dishes consisting of mainly fish and shellfish, meat, egg, vegetables and pulses. Cereals are relatively inexpensive compared with the component foods of main and side dishes in Japan, as shown in Table 1. It might be suggested that persons with limited money available for foods mainly consume cereals (mainly rice) with a poor amount or variety of main and side dishes, while persons with affordable money for foods increase the amount or variety of main and side dishes with decreasing consumption of cereals (mainly rice). This hypothesis might be supported by the decreasing consumption of rice and increasing consumption of other foods such as meat, vegetables, fish and shellfish, and pulses ${ }^{24}$ with the observed increase of Gross National Product ${ }^{25}$ in Japan from 1955 to 2000.

For nutrients, a dietary survey of French adults found that higher diet costs were associated with more nutrientdense diets ${ }^{9}$. High-fat diets were less expensive than lowfat diets in Danish children ${ }^{5}$ and French adults. These findings in Western populations are again inconsistent with our observations. We found that while higher monetary cost of dietary energy was associated with favourable nutrient intake patterns (higher consumption 
Table 4 Dietary intake according to quintile category of monetary cost of dietary energy*

\begin{tabular}{|c|c|c|c|c|c|c|c|}
\hline & \multirow[b]{2}{*}{ Total $(n=3931)$} & \multicolumn{5}{|c|}{ Quintile category of monetary cost of dietary energy (Japanese yen $\left.1000 \mathrm{kcal}^{-1}\right) \dagger$} & \multirow[b]{2}{*}{$P$ for trend $\ddagger$} \\
\hline & & $\begin{array}{c}\text { 1st }(n=786) \\
(219-400)\end{array}$ & $\begin{array}{c}\text { 2nd }(n=786) \\
(401-445)\end{array}$ & $\begin{array}{c}\text { 3rd }(n=786) \\
\quad(446-486)\end{array}$ & $\begin{array}{c}\text { 4th }(n=787) \\
(487-537)\end{array}$ & $\begin{array}{c}\text { 5th }(n=786) \\
(538-1389)\end{array}$ & \\
\hline \multicolumn{8}{|l|}{ Food intake (g $\left.1000 \mathrm{kcal}^{-1}\right)$} \\
\hline Rice & $159 \pm 70$ & $212 \pm 79$ & $171 \pm 64$ & $154 \pm 58$ & $136 \pm 56$ & $121 \pm 52$ & $<0.0001$ \\
\hline Bread & $26 \pm 20$ & $32 \pm 26$ & $29 \pm 22$ & $26 \pm 18$ & $25 \pm 17$ & $20 \pm 16$ & $<0.0001$ \\
\hline Noodles & $37 \pm 33$ & $38 \pm 38$ & $38 \pm 33$ & $38 \pm 32$ & $36 \pm 29$ & $34 \pm 30$ & 0.0024 \\
\hline Potatoes & $16 \pm 11$ & $11 \pm 8$ & $14 \pm 8$ & $16 \pm 10$ & $18 \pm 11$ & $21 \pm 15$ & $<0.0001$ \\
\hline Confectioneries & $39 \pm 18$ & $38 \pm 21$ & $40 \pm 19$ & $41 \pm 18$ & $41 \pm 17$ & $38 \pm 16$ & 0.94 \\
\hline Fat and oil & $13 \pm 7$ & $12 \pm 8$ & $13 \pm 7$ & $13 \pm 6$ & $14 \pm 6$ & $14 \pm 6$ & $<0.0001$ \\
\hline Pulses & $25 \pm 18$ & $19 \pm 16$ & $23 \pm 18$ & $24 \pm 16$ & $26 \pm 17$ & $32 \pm 19$ & $<0.0001$ \\
\hline Fish and shellfish & $30 \pm 18$ & $17 \pm 9$ & $24 \pm 10$ & $29 \pm 11$ & $34 \pm 13$ & $47 \pm 23$ & $<0.0001$ \\
\hline Meat & $34 \pm 17$ & $24 \pm 12$ & $31 \pm 14$ & $34 \pm 15$ & $39 \pm 17$ & $41 \pm 20$ & $<0.0001$ \\
\hline Eggs & $18 \pm 14$ & $17 \pm 15$ & $19 \pm 15$ & $19 \pm 13$ & $18 \pm 13$ & $18 \pm 13$ & 0.87 \\
\hline Dairy products & $84 \pm 71$ & $75 \pm 76$ & $85 \pm 74$ & $86 \pm 70$ & $83 \pm 66$ & $88 \pm 68$ & 0.0025 \\
\hline Veqetables & $127 \pm 82$ & $72 \pm 35$ & $99 \pm 46$ & $115 \pm 48$ & $142 \pm 66$ & $207 \pm 113$ & $<0.0001$ \\
\hline Fruits & $50 \pm 51$ & $31 \pm 41$ & $44 \pm 53$ & $47 \pm 41$ & $56 \pm 51$ & $69 \pm 59$ & $<0.0001$ \\
\hline Non-alcoholic, energy-containing beverages & $33 \pm 53$ & $28 \pm 41$ & $31 \pm 44$ & $35 \pm 57$ & $27 \pm 54$ & $36 \pm 64$ & 0.0003 \\
\hline \multicolumn{8}{|l|}{ Nutrient intake } \\
\hline Protein (\% of energy) & $13.3 \pm 2.1$ & $11.5 \pm 1.6$ & $12.6 \pm 1.5$ & $13.2 \pm 1.5$ & $13.8 \pm 1.6$ & $15.3 \pm 2.2$ & $<0.0001$ \\
\hline Fat (\% of energy) & $30.0 \pm 5.9$ & $26.3 \pm 6.3$ & $29.4 \pm 5.4$ & $30.6 \pm 5.2$ & $31.8 \pm 5.2$ & $32.0 \pm 5.5$ & $<0.0001$ \\
\hline Saturated fatty acid (\% of energy) & $8.0 \pm 2.1$ & $7.0 \pm 2.1$ & $7.9 \pm 1.9$ & $8.3 \pm 2.0$ & $8.6 \pm 1.9$ & $8.5 \pm 2.0$ & $<0.0001$ \\
\hline Carbohydrate (\% of energy) & $55.2 \pm 6.8$ & $60.1 \pm 6.8$ & $56.4 \pm 5.8$ & $54.8 \pm 5.6$ & $53.1 \pm 5.7$ & $51.8 \pm 6.7$ & $<0.0001$ \\
\hline Total dietary fibre $\left(\mathrm{g} 1000 \mathrm{kcal}^{-1}\right)$ & $6.5 \pm 2.0$ & $5.3 \pm 1.3$ & $5.8 \pm 1.3$ & $6.2 \pm 1.5$ & $6.7 \pm 1.7$ & $8.1 \pm 2.7$ & $<0.0001$ \\
\hline Cholesterol (mg $\left.1000 \mathrm{kcal}^{-1}\right)$ & $165 \pm 64$ & $140 \pm 67$ & $160 \pm 63$ & $167 \pm 59$ & $173 \pm 56$ & $183 \pm 65$ & $<0.0001$ \\
\hline Sodium (mg $\left.1000 \mathrm{kcal}^{-1}\right)$ & $2093 \pm 547$ & $1805 \pm 515$ & $1989 \pm 495$ & $2059 \pm 452$ & $2202 \pm 505$ & $2410 \pm 565$ & $<0.0001$ \\
\hline Potassium (mg $1000 \mathrm{kcal}^{-1}$ ) & $1099 \pm 302$ & $838 \pm 174$ & $987 \pm 184$ & $1069 \pm 185$ & $1179 \pm 219$ & $1421 \pm 345$ & $<0.0001$ \\
\hline Calcium (mg $1000 \mathrm{kcal}^{-1}$ ) & $273 \pm 102$ & $222 \pm 93$ & $257 \pm 92$ & $271 \pm 89$ & $284 \pm 90$ & $332 \pm 112$ & $<0.0001$ \\
\hline Magnesium (mg $\left.1000 \mathrm{kcal}^{-1}\right)$ & $118 \pm 29$ & $99 \pm 23$ & $109 \pm 23$ & $117 \pm 25$ & $123 \pm 23$ & $142 \pm 32$ & $<0.0001$ \\
\hline Iron (mg $\left.1000 \mathrm{kcal}^{-1}\right)$ & $3.7 \pm 0.9$ & $3.1 \pm 0.7$ & $3.4 \pm 0.7$ & $3.7 \pm 0.6$ & $3.9 \pm 0.7$ & $4.5 \pm 1.0$ & $<0.0001$ \\
\hline Vitamin A $\left(\mu \mathrm{g} 1000 \mathrm{kcal}^{-1}\right)$ & $260 \pm 169$ & $174 \pm 114$ & $220 \pm 104$ & $249 \pm 113$ & $280 \pm 124$ & $377 \pm 259$ & $<0.0001$ \\
\hline Vitamin D (mg $\left.1000 \mathrm{kcal}^{-1}\right)$ & $3.6 \pm 2.0$ & $2.3 \pm 1.3$ & $3.0 \pm 1.6$ & $3.5 \pm 1.5$ & $3.9 \pm 1.6$ & $5.2 \pm 2.6$ & $<0.0001$ \\
\hline Vitamin E $\left(\mathrm{mg} 1000 \mathrm{kcal}^{-1}\right)$ & $5.4 \pm 1.3$ & $4.3 \pm 1.1$ & $5.0 \pm 1.0$ & $5.3 \pm 0.9$ & $5.8 \pm 1.1$ & $6.5 \pm 1.3$ & $<0.0001$ \\
\hline Thiamin $\left({\left.\mathrm{mg} 1000 \mathrm{kcal}^{-1}\right)}^{\prime}\right.$ & $0.4 \pm 0.1$ & $0.3 \pm 0.1$ & $0.4 \pm 0.1$ & $0.4 \pm 0.1$ & $0.4 \pm 0.1$ & $0.5 \pm 0.1$ & $<0.0001$ \\
\hline Riboflavin (mg $1000 \mathrm{kcal}^{-1}$ ) & $0.7 \pm 0.2$ & $0.6 \pm 0.2$ & $0.6 \pm 0.2$ & $0.7 \pm 0.2$ & $0.7 \pm 0.2$ & $0.8 \pm 0.2$ & $<0.0001$ \\
\hline Vitamin C $\left(\mathrm{mg} 1000 \mathrm{kcal}^{-1}\right)$ & $47 \pm 22$ & $32 \pm 13$ & $39 \pm 16$ & $44 \pm 15$ & $52 \pm 18$ & $67 \pm 27$ & $<0.0001$ \\
\hline Energy intake (kcal day ${ }^{-1}$ ) & $1822 \pm 504$ & $1625 \pm 441$ & $1753 \pm 445$ & $1859 \pm 464$ & $1912 \pm 511$ & $1960 \pm 577$ & $<0.0001$ \\
\hline Edible weight consumed $\left(\right.$ g day $\left.^{-1}\right)$ & $1439 \pm 461$ & $1179 \pm 359$ & $1330 \pm 358$ & $1440 \pm 385$ & $1526 \pm 430$ & $1719 \pm 552$ & $<0.0001$ \\
\hline Energy density $\left(\mathrm{kcal} \mathrm{g}^{-1}\right)$ & $1.29 \pm 0.22$ & $1.40 \pm 0.24$ & $1.33 \pm 0.21$ & $1.30 \pm 0.21$ & $1.26 \pm 0.19$ & $1.16 \pm 0.20$ & $<0.0001$ \\
\hline
\end{tabular}

*Values are mean \pm standard deviation

0.008 US dollars in April 2006

Tests for linear trend used the median value in each quintile as a continuous variable in linear regression. Adjustment for possible confounding variables, including physical activity level (continuous), residential block (Hokkaido and Tohoku; Kanto; Hokuriku and Tokai; Kinki; Chugoku and Shikoku; Kyushu), size of residential area (city with $\geq 1$ million; city with $<1$ million; town and village), living status (living with family; living alone; living with others), current smoking (yes; no), current alcohol drinking (yes; no), current dietary supplement use (yes; no), currently trying to lose weight (yes; no), and rate of eating (very slow; relatively slow; medium;
relatively fast; very fast) and energy intake for variables except for energy intake (kcal day ${ }^{-1}$, continuous), did not change the results materially with the exception of noodles ( $P$ or trend $\left.=0.88\right)$, confectioneries $(P$ for trend $=0.0076$; negative relationship) and dairy products $(P$ for trend $=0.07$ ) 
Table 5 Body mass index according to quintile category of monetary cost of dietary energy $(n=3931)^{\star}$

\begin{tabular}{|c|c|c|c|c|c|c|}
\hline & \multicolumn{5}{|c|}{ Quintile category of monetary cost of dietary energy (Japanese yen $1000 \mathrm{kcal}^{-1}$ )† } & \multirow[b]{2}{*}{$P$ for trend $\neq$} \\
\hline & $\begin{array}{c}\text { 1st }(n=786) \\
(219-400)\end{array}$ & $\begin{array}{l}\text { 2nd }(n=786) \\
\quad(401-445)\end{array}$ & $\begin{array}{c}\text { 3rd }(n=786) \\
\quad(446-486)\end{array}$ & $\begin{array}{c}\text { 4th }(n=787) \\
(487-537)\end{array}$ & $\begin{array}{c}\text { 5th }(n=786) \\
(538-1389)\end{array}$ & \\
\hline \multicolumn{7}{|c|}{ Body mass index $\left(\mathrm{kg} \mathrm{m}^{-2}\right)$} \\
\hline Model $1 \S$ & $21.0 \pm 0.1$ & $21.1 \pm 0.1$ & $20.9 \pm 0.1$ & $21.0 \pm 0.1$ & $20.8 \pm 0.1$ & 0.0224 \\
\hline Model 2ब & $21.1 \pm 0.1$ & $21.1 \pm 0.1$ & $20.9 \pm 0.1$ & $21.0 \pm 0.1$ & $20.8 \pm 0.1$ & 0.0197 \\
\hline Model 3\| & $21.1 \pm 0.1$ & $21.1 \pm 0.1$ & $20.9 \pm 0.1$ & $21.0 \pm 0.1$ & $20.7 \pm 0.1$ & 0.0301 \\
\hline
\end{tabular}

*Values are mean \pm standard error.

+1 Japanese yen $=0.007$ Euros $=0.008$ US dollars in April 2006.

$\ddagger$ Tests for linear trend used the median value in each quintile as a continuous variable in linear regression.

$\S$ Crude model.

- Adjusted for physical activity level (continuous), residential block (Hokkaido and Tohoku; Kanto; Hokuriku and Tokai; Kinki; Chugoku and Shikoku; Kyushu), size of residential area (city with $\geq 1$ million; city with $<1$ million; town and village), living status (living with family; living alone; living with others), current smoking (yes; no), current alcohol drinking (yes; no), current dietary supplement use (yes; no), currently trying to lose weight (yes; no), rate of eating (very slow; relatively slow; medium; relatively fast; very fast) and energy intake (kcal day ${ }^{-1}$, continuous).

$\|$ Adjusted for variables used in the model 2 and intakes of protein (\% of energy, continuous), fat (\% of energy, continuous) and dietary fibre ( $\mathrm{g} 1000 \mathrm{kcal}^{-1}$, continuous).

of protein, dietary fibre and key vitamins and minerals), there was also a positive association for dietary fat (and saturated fat and cholesterol) and sodium and a negative association for carbohydrate. The higher fat and lower carbohydrate intake with increasing monetary cost of dietary energy seemed to be due largely to decreasing consumption of cereals (particularly rice). Higher intake of sodium might be due to higher intakes of vegetables, meat, fish and shellfish, and pulses, because in Japan these foods are usually accompanied by seasonings of salty taste, such as salt, soy sauce, miso and dressings; actually, intakes of these foods were positively correlated with sodium intake in the present study (Pearson correlation coefficient $=0.13-0.43$; median $=0.33$ )

Our finding that monetary cost of dietary energy is inversely associated with dietary energy density reflects the results of a number of other studies. Two French studies also found that energy-dense diets are associated with lower diet costs ${ }^{8,9}$. Dietary energy density is largely determined by the water content of foods ${ }^{26}$; unlike packaged energy-dense foods, which are dry and tend to have a stable shelf life (including cereals, confectioneries, and fat and oil $)^{8}$, transport, storage and wastage costs are all higher for perishable fresh produce (i.e. energy-dilute foods such as fish and shellfish, vegetables and fruit). Thus, the generally observed inverse association between energy cost and energy density can be explained by the fact that, on an energy content basis, energy-dense foods are clearly less costly than energy-dilute foods ${ }^{8}$. However, although energy density and energy intake have previously constantly been shown to be positively linked, both in experimental and epidemiological studies in Western countries ${ }^{27}$, a higher energy intake was associated with a lower energy density because energy intake was positively but energy density was negatively associated with monetary cost of dietary energy in the present study. This seemed to be due to the phenomenon that monetary cost of dietary energy was positively associated with both energy intake and edible weight consumed, and the magnitude of differences between quintiles was larger in edible weight consumed than in energy intake. This important point of disagreement between Western and Japanese studies needs to be addressed in future studies.

A Spanish study reported an association between the higher monetary costs of healthy dietary patterns and lower $\mathrm{BMI}^{10}$. Although higher monetary cost of dietary energy was not necessarily associated with healthier dietary intake patterns, there was a significant independent negative relationship between monetary cost of dietary energy and BMI in the present study. However, although the association was statistically significant, the magnitude of differences in BMI between quintiles of monetary cost of dietary energy was quite low. Additionally, our subjects were lean compared with Western populations and their BMI values have been reported, not measured, although a high correlation of BMI calculated from self-reported body weight and height with that calculated from measured values has been shown ${ }^{28,29}$, which suggests that BMI calculated from self-reported body weight and height is a reliable measure, at least for use in correlation analysis. Furthermore, although we tried to adjust for a wide range of potential confounding factors, monetary cost of dietary energy might be a surrogate of factors associated with BMI which we did not measure in the present study (e.g. socio-economic level of families), as having or using money is unlikely directly related to BMI. Thus, the public health relevance of this finding is highly uncertain.

A number of methodological limitations of this study should be mentioned. First, in the absence of actual food expenditure data, food prices were derived from the National Retail Price Survey and websites of nationally distributed supermarket and fast-food restaurant chains. As this procedure gives only an approximation of actual diet costs, the results of the present study should be interpreted with caution. We note, however, that a similar methodology has been used in all previous observational studies $^{5-10}$ 
Second, although we used a validated $\mathrm{DHQ}^{13-15}$, the underreporting of dietary intake remains a serious con$\operatorname{cern}^{30}$. To minimise the influence of dietary underreporting, we used energy-adjusted values. Studies have consistently shown that underreporting is more prevalent among people with higher $\mathrm{BMI}^{30,31}$, and that energydense, nutrient-dilute and low-cost foods such as fat and oils, sugar and confectioneries are more likely to be selectively underreported ${ }^{30,32}$. However, as mentioned above, exclusion of energy underreporters identified by the Goldberg cut-off method ${ }^{21,23}$ did not change the results materially, which may support the robustness of the findings in the present study.

Several intervention studies in the USA reported nutrient-dense diets that were not more expensive than lowerquality diets ${ }^{33-35}$. These intervention studies provided individual instruction on how to identify nutritious lowcost foods, how and where to make food purchases, and how to store and prepare the foods, possibly facilitating the consumption of a healthier diet at lower cost. However, the observational nature of the present study did not allow us to investigate directly the cost of dietary change following nutritional intervention.

Finally, because our subjects were selected female dietetic students, we may not be able to extrapolate our results to the general Japanese population. To minimise the influence of nutritional education, the present survey was conducted in most institutions within 2 weeks after the course began. As the subjects are likely to have a high level of nutrition knowledge and elevated rates of social desirability concerning diet, health and body weight, they are also likely to report lower body weights (and higher body heights) and lower energy intakes than average. However, mean values of BMI and energy intake in our subjects $\left(21.0 \mathrm{~kg} \mathrm{~m}^{-2}\right.$ and $1822 \mathrm{kcalday}^{-1}$, respectively) were highly comparable with those in a representative sample of Japanese women aged $15-19$ years $\left(21.0 \mathrm{~kg} \mathrm{~m}^{-2}\right.$ and $1858 \mathrm{kcal} \mathrm{day}^{-1}$, respectively) ${ }^{12}$.

In conclusion, monetary cost of dietary energy was associated with not only favourable but also unfavourable aspects of dietary intake among a large group of young Japanese women. Additionally, monetary cost of dietary energy was inversely associated with BMI, although the magnitude was quite low. Because the relationship between dietary cost, nutrient and food intakes and BMI is an important public health topic, our observation in a selected population should be confirmed using more precise evaluation of diet costs or actual food expenditures in a more representative sample of the Japanese population.

\section{Acknowledgements}

Sources of funding: This work was supported by grants from the Japanese Ministry of Health, Labour and Welfare. Conflict of interest declaration: None of the authors has any conflict of interest to declare.
Autborship responsibilities: K.M. was involved in designing the study, data collection and data management, conducted the statistical analyses, and wrote the manuscript. S.S. was responsible for designing the study, data collection and data management, the overall management, and assisted in manuscript preparation. H.O. was involved in the study design. Y.T. assisted in the manuscript preparation. Y.H. was involved in study design, data collection and data management. M.I. was involved in data collection and data management. All of the authors provided suggestions during the preparation of the manuscript and approved the final version submitted for publication.

\section{References}

1 Shepherd R. Resistance to changes in diet. Proceedings of the Nutrition Society 2002; 61: 267-72.

2 Glanz K, Basil M, Maibach E, Goldberg J, Snyder D. Why Americans eat what they do: taste, nutrition, cost, convenience, and weight control concerns as influences on food consumption. Journal of the American Dietetic Association 1998; 98: 1118-26.

3 Lennernas M, Fjellstrom C, Becker W, Giachetti I, Schmitt A, Remaut de Winter A, et al. Influences on food choice perceived to be important by nationally-representative samples of adults in the European Union. European Journal of Clinical Nutrition 1997; 51(Suppl.): S8-15.

4 Drewnowski A, Darmon N. The economics of obesity: dietary energy density and energy cost. American Journal of Clinical Nutrition 2005; 82(Supp.1): 265S-73S.

5 Stender S, Skovby F, Haraldsdottir J, Andresen GR, Michaelsen KF, Nielsen BS, et al. Cholesterol-lowering diets may increase the food costs for Danish children. A crosssectional study of food costs for Danish children with and without familial hypercholesterolaemia. European Journal of Clinical Nutrition 1993; 47: 776-86.

6 Cade J, Upmeier H, Calvert C, Greenwood D. Costs of a healthy diet: analysis from the UK Women's Cohort Study. Public Health Nutrition 1999; 2: 505-12.

7 Drewnowski A, Darmon N, Briend A. Replacing fats and sweets with vegetables and fruits - a question of cost. American Journal of Public Health 2004; 94: 1555-9.

8 Darmon N, Briend A, Drewnowski A. Energy-dense diets are associated with lower diet costs: a community study of French adults. Public Health Nutrition 2004; 7: 21-7.

9 Andrieu E, Darmon N, Drewnowski A. Low-cost diets: more energy, fewer nutrients. European Journal of Clinical Nutrition 2006; 60: 434-6.

10 Schroder H, Marrugat J, Covas MI. High monetary costs of dietary patterns associated with lower body mass index: a population-based study. International Journal of Obesity 2006; 30: 1574-9.

11 Sasaki S, Takahashi T, Iitoi Y, Iwase Y, Kobayashi M, Ishihara J, et al. Food and nutrient intakes assessed with dietary records for the validation study of a self-administered food frequency questionnaire in JPHC Study Cohort I. Journal of Epidemiology 2003; 13: S23-50.

12 Ministry of Health, Labour and Welfare. The National Nutrition Survey in Japan, 2002. Tokyo: Ministry of Health, Labour and Welfare, 2004 (in Japanese).

13 Sasaki S, Yanagibori R, Amano K. Self-administered diet history questionnaire developed for health education: a relative validation of the test-version by comparison with 3-day diet record in women. Journal of Epidemiology 1998; 8: 203-15. 
14 Sasaki S, Yanagibori R, Amano K. Validity of a self-administered diet history questionnaire for assessment of sodium and potassium: comparison with single 24-hour urinary excretion. Japanese Circulation Journal 1998; 62: 431-5.

15 Sasaki S, Ushio F, Amano K, Morihara M, Todoriki T, Uehara Y, et al. Serum biomarker-based validation of a self-administered diet history questionnaire for Japanese subjects. Journal of Nutritional Science and Vitaminology 2000; 46: 285-96.

16 Science and Technology Agency. Standard Tables of Food Composition in Japan, 5th ed.. Tokyo: Printing Bureau of the Ministry of Finance, 2000 (in Japanese).

17 Price Statistics Office, Statistics Bureau. Retail Price Survey [online]. Available at http://www.stat.go.jp/data/kouri/ index.htm. Accessed 1 April 2006 (in Japanese).

18 Ainsworth BE, Haskell WL, Leon AS, Jacobs Jr. DR, Montoye HJ, Sallis JF, et al. Compendium of physical activities: classification of energy costs of human physical activities. Medicine and Science in Sports and Exercise 1993; 25: 71-80.

19 Ainsworth BE, Haskell WL, Whitt MC, Irwin ML, Swartz AM, Strath SJ, et al. Compendium of physical activities: an update of activity codes and MET intensities. Medicine and Science in Sports and Exercise 2000; 32(Suppl.): S498-504.

20 Ministry of Health, Labour and Welfare. Dietary Reference Intakes for Japanese, 2005. Tokyo: Daiichi Shuppan Publishing Co. Ltd, 2005 (in Japanese).

21 Goldberg GR, Black AE, Jebb SA, Cole TJ, Murgatroyd PR, Coward WA, et al. Critical evaluation of energy intake data using fundamental principles of energy physiology: 1. Derivation of cut-off limits to identify under-recording. European Journal of Clinical Nutrition 1991; 45: 569-81.

22 Black AE, Goldberg GR, Jebb SA, Livingstone MBE, Cole TJ, Prentice AM. Critical evaluation of energy intake data using fundamental principles of energy physiology: 2. Evaluating the results of published surveys. European Journal of Clinical Nutrition 1991; 45: 583-99.

23 Black AE. Critical evaluation of energy intake using the Goldberg cut-off for energy intake:basal metabolic rate. A practical guide to its calculation, use and limitations. International Journal of Obesity and Related Metabolic Disorders 2000; 24: 1119-30.

24 Ministry of Health, Labour and Welfare. The National Nutrition Survey in Japan, 1955-2000. Tokyo: Ministry of Health, Labour and Welfare, 1957-2002 (in Japanese).
25 Ministry of Health, Labour and Welfare. Statistical tables: trend of medical expenditure, Gross National Product, and Net National Income in Japan [online]. Available at http:// www1.mhlw.go.jp/toukei/k-iryohi/hyo1.html. Accessed 3 October 2006 (in Japanese).

26 Stubbs J, Ferres S, Horgan G. Energy density of foods: effects on energy intake. Critical Reviews in Food Science and Nutrition 2000; 40: 481-15.

27 Poppitt SD, Prentice AM. Energy density and its role in the control of food intake: evidence from metabolic and community studies. Appetite 1996; 26: 153-74.

28 Goodman E, Hinden BR, Khandelwal S. Accuracy of teen and parental reports of obesity and body mass index. Pediatrics 2000; 106: 52-8.

29 Kuczmarski MF, Kuczmarski RJ, Najjar M. Effects of age on validity of self-reported height, weight, and body mass index: findings from the Third National Health and Nutrition Examination Survey, 1988-1994. Journal of the American Dietetic Association 2001; 101: 28-34.

30 Livingstone MBE, Black AE. Markers of the validity of reported energy intake. Journal of Nutrition 2003; 133: 895S-920S.

31 Okubo H, Sasaki S. Underreporting of energy intake among Japanese women aged 18-20 years and its association with reported nutrient and food group intakes. Public Health Nutrition 2004; 7: 911-17.

32 Lafay L, Mennen L, Basdevant A, Charles MA, Borys JM, Eschwege $\mathrm{E}$, et al. Does energy intake underreporting involve all kinds of food or only specific food items? Results from the Fleurbaix Laventie Ville Sante (FLVS) study. International Journal of Obesity and Related Metabolic Disorders 2000; 24: 1500-6.

33 Mitchell DC, Shannon BM, McKenzie J, Smiciklas-Wright H, Miller BM, Tershakovec AM. Lower fat diets for children did not increase food costs. Journal of Nutrition Education 2000; 32: 100-3.

34 Burney J, Haughton B. EFNEP: a nutrition education program that demonstrates cost-benefit. Journal of the American Dietetic Association 2002; 102: 39-45.

35 Raynor HA, Kilanowski CK, Esterlis I, Epstein LH. A costanalysis of adopting a healthful diet in a family-based obesity treatment program. Journal of the American Dietetic Association 2002; 102: 645-56. 